\title{
Modelling the transmission of healthcare associated infections: a systematic review
}

\author{
Esther van Kleef ${ }^{1,2^{*}}$, Julie V Robotham ${ }^{1,2}$, Mark Jit ${ }^{1,2}$, Sarah R Deeny ${ }^{2}$ and William J Edmunds ${ }^{1}$
}

\begin{abstract}
Background: Dynamic transmission models are increasingly being used to improve our understanding of the epidemiology of healthcare-associated infections (HCAI). However, there has been no recent comprehensive review of this emerging field. This paper summarises how mathematical models have informed the field of HCAl and how methods have developed over time.

Methods: MEDLINE, EMBASE, Scopus, CINAHL plus and Global Health databases were systematically searched for dynamic mathematical models of HCAl transmission and/or the dynamics of antimicrobial resistance in healthcare settings.

Results: In total, 96 papers met the eligibility criteria. The main research themes considered were evaluation of infection control effectiveness (64\%), variability in transmission routes (7\%), the impact of movement patterns between healthcare institutes (5\%), the development of antimicrobial resistance (3\%), and strain competitiveness or cocolonisation with different strains (3\%). Methicillin-resistant Staphylococcus aureus was the most commonly modelled HCAl (34\%), followed by vancomycin resistant enterococci (16\%). Other common HCAls, e.g. Clostridum difficile, were rarely investigated (3\%). Very few models have been published on HCAl from low or middle-income countries. The first HCAl model has looked at antimicrobial resistance in hospital settings using compartmental deterministic approaches. Stochastic models (which include the role of chance in the transmission process) are becoming increasingly common. Model calibration (inference of unknown parameters by fitting models to data) and sensitivity analysis are comparatively uncommon, occurring in 35\% and 36\% of studies respectively, but their application is increasing. Only $5 \%$ of models compared their predictions to external data.

Conclusions: Transmission models have been used to understand complex systems and to predict the impact of control policies. Methods have generally improved, with an increased use of stochastic models, and more advanced methods for formal model fitting and sensitivity analyses. Insights gained from these models could be broadened to a wider range of pathogens and settings. Improvements in the availability of data and statistical methods could enhance the predictive ability of models.
\end{abstract}

Keywords: Mathematical modelling, Healthcare-associated infections, Epidemiology

\section{Background}

Healthcare-associated infections (HCAI) continue to cause a major burden on society, affecting more than 4 million patients annually in Europe alone, and causing an estimated 16 million additional bed-days responsible for $€ 7$ billion in direct medical costs [1]. In the United

\footnotetext{
* Correspondence: esther.vankleef@lshtm.ac.uk

'Infectious Disease Epidemiology Department, Faculty of Epidemiology and Population Health, Centre of Mathematical Modelling, London School of Hygiene and Tropical Medicine, London, UK

${ }^{2}$ Modelling and Economics unit, Public Health England, Colindale, London, UK
}

Kingdom, interventions such as improved hand hygiene, antibiotic stewardship and screening combined with decolonisation are believed to have set off a steep reduction in reported incidence of health care-associated methicillinresistant Staphylococcus aureus (MRSA) bacteraemia and Clostridium difficile infection with peak incidence in 2003/04 and 2007/08 respectively [2]. Further progress in reducing the burden of HCAI is hindered by uncertainty surrounding the role of asymptomatic carriers [3,4], environmental transmission [5-7] and the recent emergence of bacteria other than MRSA and C. difficile, such as 
enterobacteriaceae (e.g. Escherichia coli) [8]. Mathematical models are increasingly being used to obtain a deeper understanding of epidemiological patterns in hospital infections and to guide hospital infection control policy decisions, as is seen in other areas of infectious disease epidemiology [9].

A previous review of the area provided insight into the type of models used for hospital epidemiology and highlighted their capacity to increase epidemiological understanding, and inform infection control policy [10]. This review, conducted in 2006, primarily aimed to explain the capacities of models and therefore was limited to a detailed description of a number of studies. Hence, the emerging trends in the area were not fully explored. Since 2006 the field has expanded considerably. We conducted a systematic review in order to establish how mathematical models have been applied in the field of HCAI, and how model methods have developed over time.

\section{Methods}

We searched Medline (1950 to present), EMBASE (1947 to present), Scopus (1823 to present), CINAHL (1937 to present) and Global health (1910 to present). Results were limited to peer-reviewed publications in English. Search terms and Medical Subject Headings (MeSH) for nosocomial organisms and antibiotic resistance were combined with search and $\mathrm{MeSH}$ terms for healthcare settings and mathematical models as follows:

- Nosocomial infections in general (e.g."healthcareassociated infection \$" or "hospital-acquired infection\$")

\section{OR}

- Nosocomial organisms (e.g. "C. difficile” or "Staphylococcus aureus") OR Antimicrobial resistance AND Nosocomial (e.g. "hospital\$” or "healthcare")

\section{AND}

- Mathematical modelling or economic evaluation model (e.g. "stochastic" or "deterministic" AND "model")

We decided not to use search terms for nosocomial infection types (e.g. surgical site infections or urinary tract infections), since our review focuses on the transmission of infections from one individual to another, which cannot generally be accurately represented without knowing the causative organism.

The complete search strategy is provided in the Additional file 1. All databases were search identically, with exception of the MeSH terms, which were altered to the subject-heading dictionary used in each particular database. The final search was conducted on 11 December 2011. Each title and abstract in the search result was independently screened by EvK and at least one of the other authors. Full text evaluation was conducted by EvK and in case of uncertainty, discussion took place with JR.

\section{Inclusion criteria}

Eligible studies had to fulfil the following criteria: 1) mathematical modelling of HCAI transmission and/or the dynamics of antimicrobial resistance; 2) dynamic transmission models only (i.e. a model which tracks the number of individuals (or proportion of a population) carrying or infected with a pathogen over time, while capturing the effect of contact between individuals on transmission [9]); 3) a primary focus on HCAI transmission in healthcare settings.

\section{Exclusion criteria}

Studies were excluded if they did not involve: 1) human to human transmission; or did involve 2) within host transmission only; 3) pharmacodynamics and pharmacokinetics of drugs (e.g. the impact of antibiotic exposure, exploring antibiotic tolerance and investigating fitness), 4) animal transmission of HCAI; 5) community transmission of pathogens spread in the healthcare environment as well, where community spread was the focus of the paper (e.g. SARS epidemics); or 6) literature review without new primary studies. Moreover, no editorials or letters to editors were included, except if a new mathematical model was introduced.

\section{Results}

The database search retrieved 2461 unique papers (Figure 1). After screening the titles and abstracts, 302 papers met the inclusion criteria and were thus eligible for full text evaluation. Review of the full text publications resulted in the inclusion of 94 relevant papers based on our selection criteria. An additional two papers were identified via reference screening $[11,12]$.

The distribution of these 96 papers over time demonstrates that HCAI transmission models have been increasingly employed since the introduction of the first model of nosocomial pathogens' spread [13] (Figure 2).

\section{Objectives of mathematical models of HCAls Pathogens modelled}

Although HCAIs are often associated with antibioticresistant bacteria, HCAI models have involved antimicrobial susceptible pathogens as well. In this review, studies that did not specify a particular pathogen of concern, but that claimed to investigate antimicrobial resistant bacteria, 


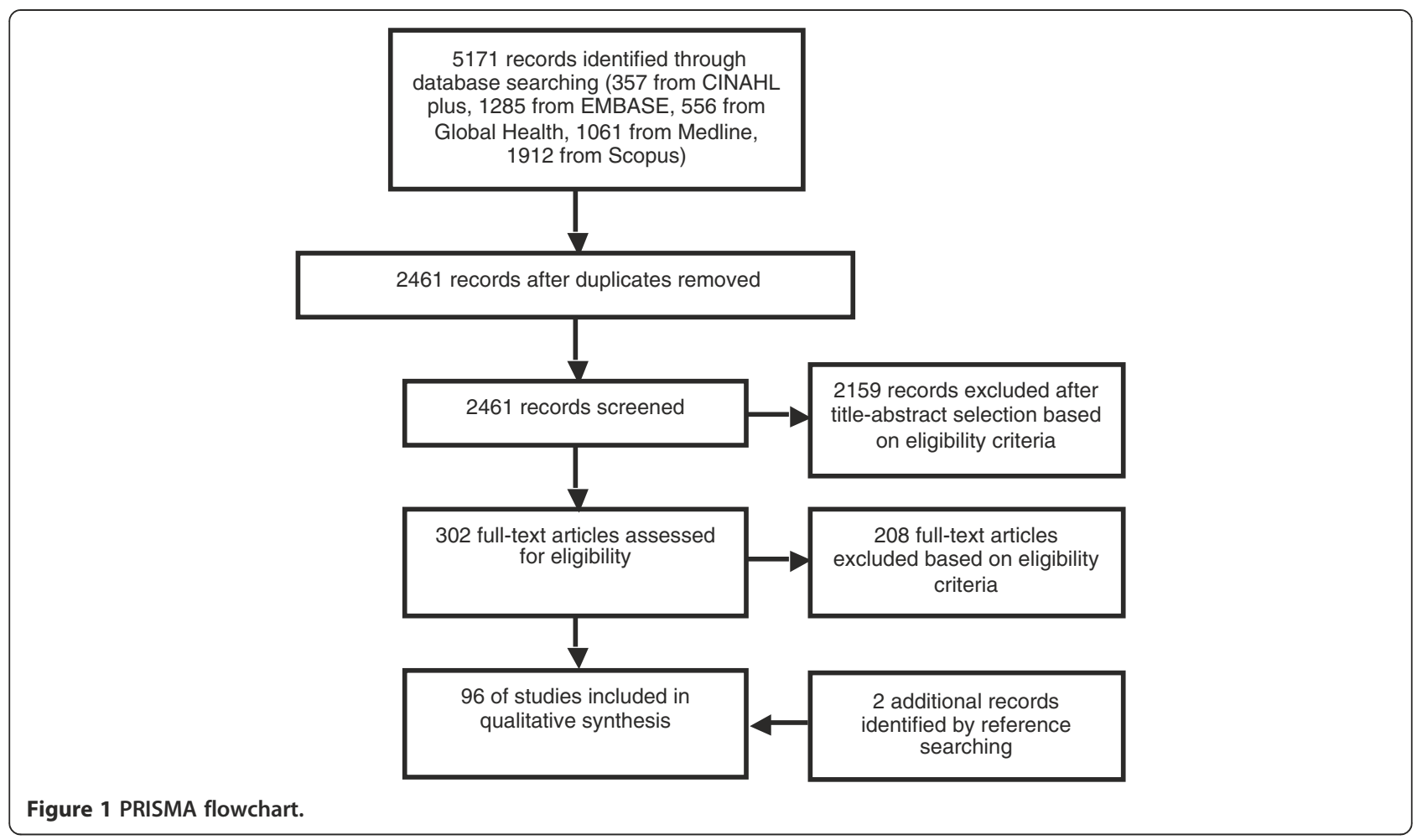

were classified as antimicrobial resistant bacteria (ARB). Otherwise, the study was categorised as 'HCAI in general'. Moreover, as the majority of patients can carry HCAI such as MRSA and C. difficile asymptomatically, many mathematical models simulate the epidemiology of colonisation, however for brevity we have referred to all models as concerning the epidemiology of HCAI in the text.

Figure 3 shows that MRSA was the most common bacterial species studied (34\%; 33 studies) [14-46], followed by Vancomycin-resistant Enterococcus (VRE) (or glycopeptide-resistant enterococci) (16\%; 15 studies) $[12,18,28,31,47-57]$ whereas $C$. difficile has rarely been the subject of a model (3\%; 3 studies) [58-60]. As several studies investigated the dynamics of more than one pathogen, the total number of infection agents $(\mathrm{N}=102)$ listed in Figure 3 exceeds the total number of studies $(\mathrm{N}=96)$.

\section{Intervention effectiveness}

The first model of HCAI conceptualised the spread of antibiotic resistance in bacterial populations among hospital patients [13]. This was soon followed by models evaluating the effectiveness of interventions to reduce antibiotic resistance (e.g. antibiotic cycling or mixing).

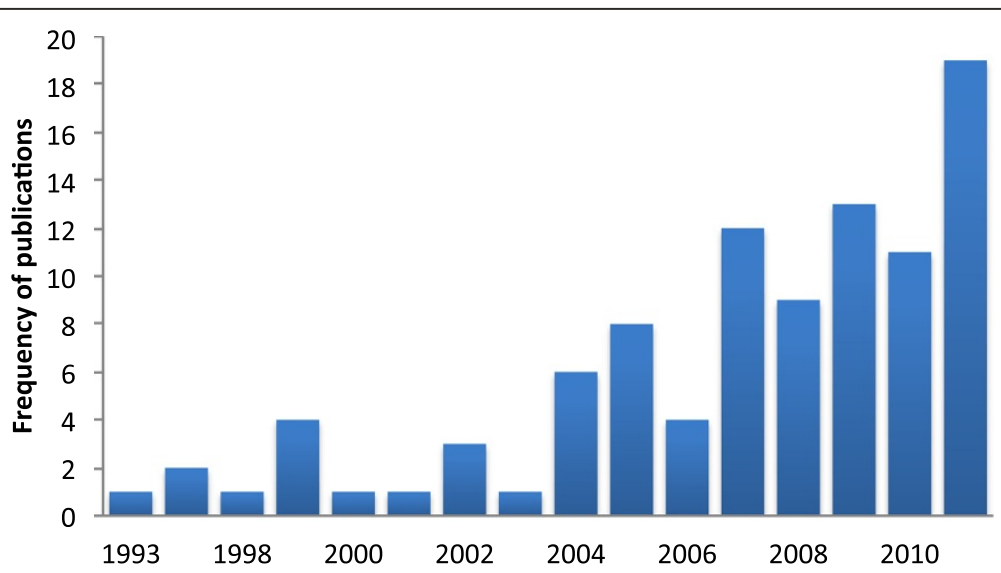

Figure 2 Number of HCAI modelling publications over time (1993-2011). Number of studies identified on modelling of HCAl and antimicrobial resistance spread in a nosocomial setting according to year of publication. 


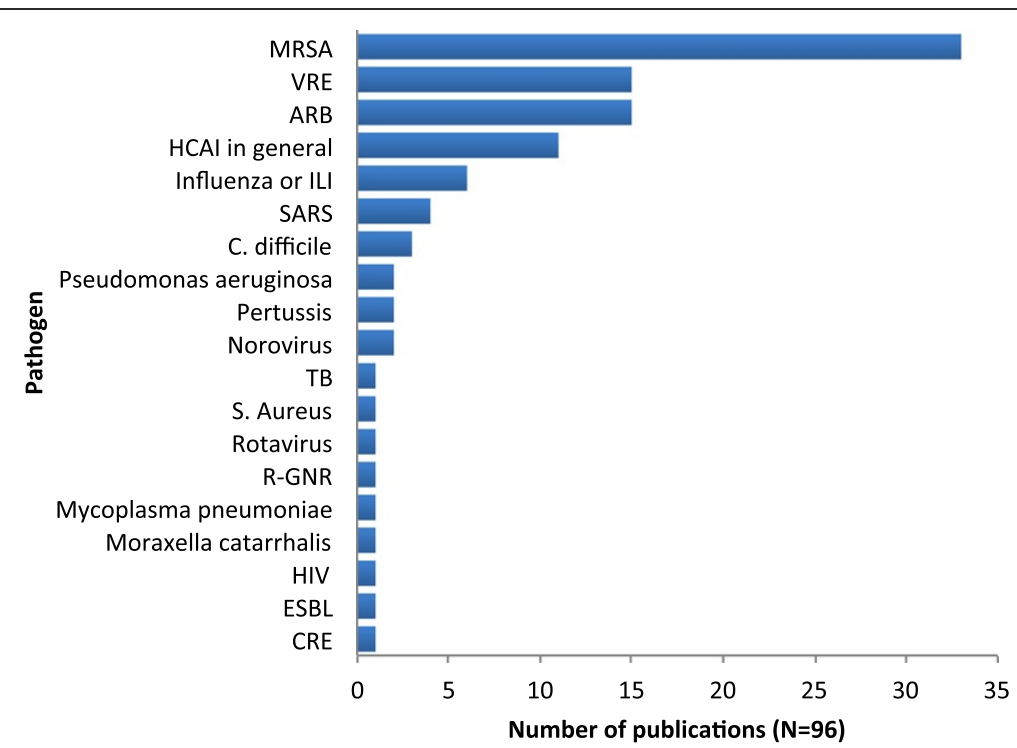

Figure 3 Pathogens modelled in a nosocomial setting (1993-2011). Number of studies identified on nosocomial infection transmission according to pathogen type. MRSA= Methicillin resistant Staphylococcus aureus; ARB = Antimicrobial resistant bacteria; VRE = Vancomycin-resistant Enterococcus; $\mathrm{HCAI}=$ Healthcare associated infections; ILI = Influenza-like illness; SARS = Severe acute respiratory syndrome; TB= Tuberculosis; R-GNR= Third generation cephalosporin-resistant Gram-negative rods; HIV = Human immunodeficiency virus; ESBL = Extended-Spectrum Beta-Lactamases; CRE = cephalosporin-resistant Enterobacteriaceae.

Since then, most HCAI models have aimed to quantify infection control effectiveness $(64 \% ; 62$ studies). The infection control measures most frequently considered among these 62 papers have been: hand hygiene (37\%; 23 studies), patient isolation (24\%; 15 studies), HCW cohorting (23\%; 14 studies), antibiotic stewardship (21\%; 13 studies), and screening (18\%, 11 studies). Figure 4 provides an overview of the main interventions modelled over time, emphasising that decolonisation and vaccination are more recent subjects of study. Moreover,

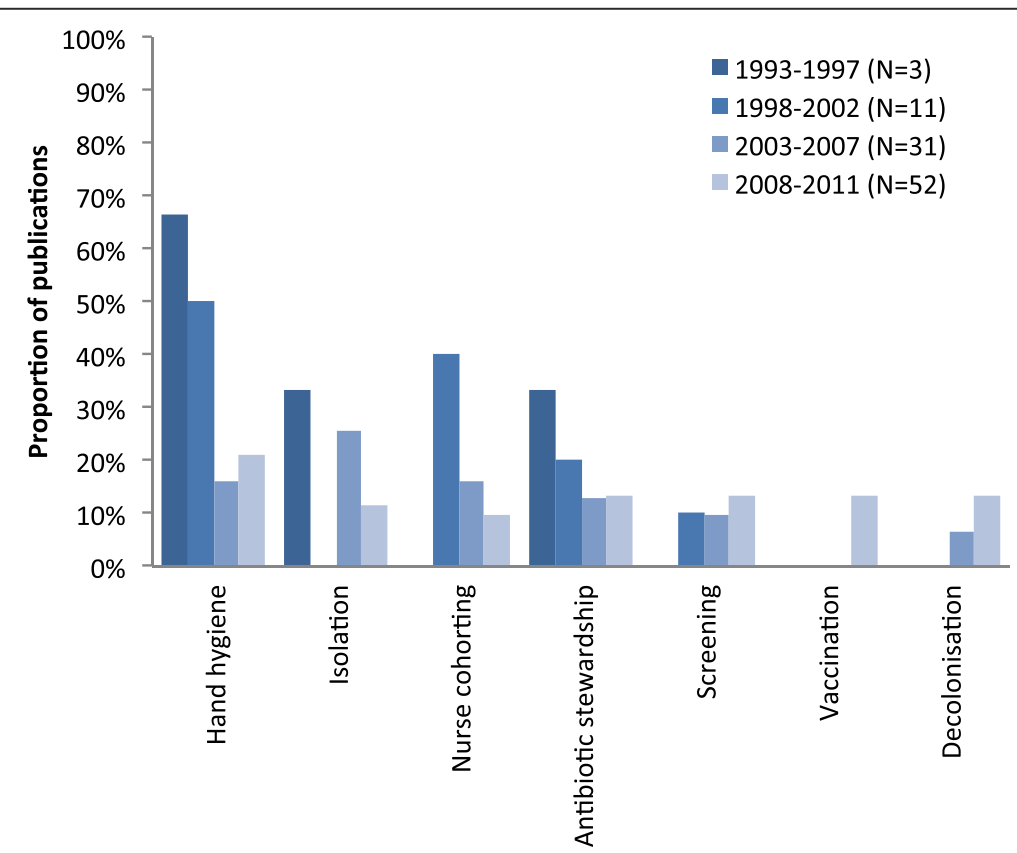

Figure 4 Main interventions evaluated over time (1993-2011). Main interventions evaluated over time (1993-2011). Illustration of the proportionate distribution of the seven most commonly investigated interventions by means of a modelling framework by the total number of publications in each time period. 
a wider variability of interventions has been evaluated in the later years. Table 1 illustrates the type of interventions that have been evaluated for each HCAI pathogen.

\section{Furthering epidemiological understanding}

Models are often used to increase epidemiological understanding. Hospital surveillance data, which is frequently used to inform HCAI models, can lack detail in what is needed for modelling purposes. For example, information on asymptomatic carriage and timing of events (e.g. infection) are often lacking. Several studies use new statistical methods to overcome such difficulties $[31,36,48]$ and to allow for estimation of important epidemiological parameters (e.g. transmission rates) from different data sources, varying from routinely collected hospital data [56,57] to strain typing [63] or genotype data [64]. Others use modelling techniques to determine the relative importance of potential transmission reservoirs or acquisition routes (of $C$. difficile $[58,60]$, VRE [50,53], cephalosporin-resistant Enterobacteriaceae (CRE) [65] and SARS [66].

The ecological dynamics of pathogens have also been explored using models, including antimicrobial resistance $[13,67,68]$; co-colonisation with different pathogen strain types $[27,46]$ and competition between strains [24]. Another more recent subject of study is the potential impact of readmission of patients from settings such as long-term care facilities (LTCFs) or the community, as well as general movement patterns between healthcare institutes and/or the community on the transmission of MRSA [19,25,38,69], antimicrobial resistance [70] and HCAI in general [71].

Economic outcomes were not considered in dynamic transmission models until 2011 [14,23,72]. Three recent papers applied dynamic modelling techniques to estimate the economic burden of disease (MRSA) [22] and norovirus [69], and to investigate economic incentives for infection control investments [73].

\section{Country of study}

A number of studies (36\%, 32 studies) did not specify a particular national setting. Of the publications that did; only three studies (3\%) explored transmission of HCAI in lower and lower middle income countries [22,74,75] and another three looked at upper middle income China $[15,66,76]$. Studies have mainly concentrated on the United States (16\%; 15 studies), the United Kingdom (13\%; 12 studies) and the Netherlands (10\%; 10 studies).

Table 1 Definitions of modelling terms

\begin{tabular}{|c|c|}
\hline Term & Definition \\
\hline Deterministic model & $\begin{array}{l}\text { A model in which there is no role of chance in the evolution of the states of the system, i.e. the model is } \\
\text { 'predetermined' by the parameters and initial conditions [61]. }\end{array}$ \\
\hline Stochastic model & $\begin{array}{l}\text { A model in which random (stochastic) processes can affect whether certain events or processes occur (e.g. the rate } \\
\text { at which individuals are infected can vary by chance) [61]. }\end{array}$ \\
\hline Compartmental model & $\begin{array}{l}\text { A model in which the population is divided into subgroups (i.e. compartments), which represent the average values } \\
\text { of individuals in a particular state (e.g. susceptible, infectious or recovered). Within each compartment, all individuals } \\
\text { are homogenous [9]. }\end{array}$ \\
\hline Individual-based model & $\begin{array}{l}\text { A model in which single individuals are tracked rather than subgroups. Hence, each individual can be assigned } \\
\text { different characteristics such as the probability of acquiring infection or causing transmission [9]. }\end{array}$ \\
\hline $\begin{array}{l}\text { Model fitting/ model } \\
\text { calibration }\end{array}$ & $\begin{array}{l}\text { The inference of unknown parameters by choosing their values in order to approximate a set of data as well as } \\
\text { possible. Examples of model fitting methods are least squares approximation maximum likelihood estimation and } \\
\text { Markov Chain Monte Carlo Methods [62]. }\end{array}$ \\
\hline Model validation & $\begin{array}{l}\text { Comparison of model predictions to external data, that is a model should be validated against observations from } \\
\text { alternative data to the data used for model fitting [62]. }\end{array}$ \\
\hline $\begin{array}{l}\text { Univariate sensitivity } \\
\text { analysis }\end{array}$ & $\begin{array}{l}\text { Investigation of uncertainty in model parameters and its impact on model predictions by means of altering one } \\
\text { parameter at a time whilst holding others at their base-case value. }\end{array}$ \\
\hline $\begin{array}{l}\mathrm{Bi} / \text { multivariate sensitivity } \\
\text { analysis }\end{array}$ & $\begin{array}{l}\text { Investigation of uncertainty in model parameters by means of alteration of two (or more) parameters at a time whilst } \\
\text { holding others at their base-case value. }\end{array}$ \\
\hline $\begin{array}{l}\text { Probabilistic sensitivity } \\
\text { analysis }\end{array}$ & $\begin{array}{l}\text { A type of multivariate sensitivity analysis where multiple runs of the model are performed with random selection of } \\
\text { input parameters. }\end{array}$ \\
\hline $\begin{array}{l}\text { Dynamic transmission } \\
\text { model }\end{array}$ & $\begin{array}{l}\text { A model which tracks the number of individuals (or proportion of a population) carrying or infected with a pathogen } \\
\text { over time, where the risk of transmission to susceptible at a given point in time is dependent on the number of } \\
\text { infected (or colonised) individuals in the community [9]. }\end{array}$ \\
\hline Static model & $\begin{array}{l}\text { A model where the transmission risk is treated as a parameter exogenous to the model, i.e. it does not change with } \\
\text { the number of infectious individuals in the population [9]. }\end{array}$ \\
\hline Force of infection & The rate at which infected individuals become infected per unit time [61] \\
\hline
\end{tabular}




\section{Methods employed for mathematical modelling of HCAls Stochastic vs. deterministic}

The first HCAI models captured transmission dynamics in single wards using deterministic approaches $[13,16]$. As the population size in a single ward or hospital is likely to be small, a stochastic modelling approach may often be more appropriate as it can take account of the role of chance in determining transmission patterns. In Table 2, a definition of the modelling terms used for model classification is provided. Figure 5a shows that the proportion of stochastic models has increased steadily over time, and as Figure 6 illustrates, stochasticity was soon introduced (in 1997) [77] after publication of the first (deterministic) HCAI model. Several studies developed both a stochastic and a deterministic version of a similar compartmental model to investigate whether projected intervention effects were partly a result of random fluctuation [18,35,40,78-80]. Others use a deterministic model to interpret the findings of a stochastic model [81].

\section{Compartmental vs. individual-based}

Infectious disease models can have either an aggregate (or compartmental) structure (which tracks groups in the population) or an individual-based structure (which tracks individuals). The latter enables better incorporation of heterogeneity in patient characteristics such as patient demographics, contact patterns and disease history, but at the cost of increased computational burden. To date, most (73\%; 70 studies) HCAI models have taken an aggregate approach, although the proportion of individual-based models has increased over time (Figure 5a). In total, 26 publications (27\%) took an individual-based approach of which seven papers (8\%) used both compartmental and individual-based modelling [25,34,60,72,83,95,96].

\section{Model fitting to data}

Model parameter values can be based on existing studies, assumptions, or estimated directly from data [103]. Unknown parameters, such as infection transmission rates, can be inferred by calibrating a model to empirical data. With the increasing availability of computational power, numerically-intensive statistical methods for parameter inference have become more accessible. As Figure 5b shows, although only 35\% (34 studies) of HCAIs models have incorporated some sort of calibration process to empirical data, this proportion has increased over time. Metrics used to quantify goodness of fit include the least square criterion (minimisation of sums of squares between the observed data and the model predictions) $[21,56,57,75]$, maximum likelihood estimation (identification of the parameter value(s) that makes the observed data most likely) [18,22,24,35,53,63,65,66] and since 2007, Bayesian methods; frequently using
Markov Chain Monte Carlo (MCMC) approaches $[19,32,40,41,50,58,64,76]$ or a combination of MCMC and maximum likelihood estimation [36,59]. A further seven studies reported fitting their models by comparing model predictions to observed epidemiological data but did not apply any formal quantitative approach $[17,29,43,60,81,101,104]$.

\section{Uncertainty in model predictions}

Infectious disease models are developed and informed using a combination of available evidence, for example on infection transmission, disease natural history and intervention effectiveness. As availability of such information is unlikely to be complete, mathematical models inherently include some degree of uncertainty. This uncertainty may relate to model parameter values, model structure (e.g. in terms of disease states incorporated and the relationship between them) or methodology used $[9,105]$.

Parameter uncertainty was investigated by $36 \%$ of the studies (35 publications). As Figure 5b illustrates, similar trends as seen for the application of formal model calibration apply for the inclusion of parameter uncertainty. Also the methods used for parameter uncertainty have become more complex over time (Figure 5c). Of the 35 studies that have investigated parameter uncertainty, univariate sensitivity analysis (i.e. alteration of one parameter at a time whilst holding others at their base-case value) was conducted by $43 \%$ (15 studies) $[18,28,29,43,44,46,60,63,69,77,81,83,89,91,99]$. The more computationally expensive probabilistic sensitivity analysis (formulation of uncertainty in the model inputs by a joint probability distribution, and propagating this uncertainty to the outputs [106]) is in general considered a rigorous method to account for uncertainty in the joint distribution of the parameters. This was employed by 51\% (18 studies) $\quad[14,32,36,40-42,48,50,57-59,64,75,76,78,95,96,98]$ among which Latin Hypercube Sampling (LHS) as a means of performing probabilistic sensitivity analysis was conducted by four studies [75,95,96,98]. Probabilistic sensitivity analysis utilizing LHS provides a rigorous method of incorporating and representing real uncertainty surrounding parameter estimates into model-based analysis where joint probability distributions for parameters are available.

\section{Model validation}

Model validation is rare in HCAI modelling. Ideally, a model should be validated by means of comparing the model predictions with observations from an alternative dataset than the one used for model fitting, although this is often difficult in practice. Four studies (5\%) reported some kind of model validation based on at least two different data sets [50,53,75,101]. However, only one study used a statistical approach [101], whereas the 
Table 2 Healthcare infection control interventions evaluated by a modelling framework (1997-2011)

\begin{tabular}{|c|c|c|c|}
\hline Pathogen & $\begin{array}{l}\text { Interventions } \\
\text { studied }\end{array}$ & $\begin{array}{l}\text { First } \\
\text { published }\end{array}$ & References \\
\hline \multirow[t]{9}{*}{ MRSA } & Hand hygiene & 1997 & $\begin{array}{l}{[15-17,28,29,33,34,37,} \\
40,44-46]\end{array}$ \\
\hline & Antibiotic stewardship & 1997 & {$[16,21]$} \\
\hline & Isolation & 1997 & {$[14,16,26,32,35,41,42,45]$} \\
\hline & HCW cohorting & 2002 & {$[17,29,40,44,45]$} \\
\hline & Screening & 2005 & {$[14,23,25,32,34,39,44,45]$} \\
\hline & Decolonisation & 2009 & {$[14,25,26,33,34,40,45,46]$} \\
\hline & Patient cohorting & 2007 & {$[40]$} \\
\hline & Gown and glove use & 2009 & {$[32]$} \\
\hline & Other & 2006 & {$[43]$} \\
\hline \multirow[t]{8}{*}{ VRE } & Hand hygiene & 1998 & {$[12,21,28,47,49,51,54,55]$} \\
\hline & Antibiotic stewardship & 1999 & {$[47,51,55]$} \\
\hline & Isolation & 2004 & {$[12,52]$} \\
\hline & HCW cohorting & 1998 & {$[12,49,51,54,55]$} \\
\hline & Screening & 2004 & {$[47,52]$} \\
\hline & Decolonisation & 2007 & {$[50]$} \\
\hline & Patient cohorting & 2008 & {$[47]$} \\
\hline & $\begin{array}{l}\text { Environmental } \\
\text { cleaning }\end{array}$ & 2008 & {$[47]$} \\
\hline C. difficile & Other & 2009 & {$[59]$} \\
\hline \multirow[t]{3}{*}{ ARB } & Hand hygiene & 1997 & {$[82]$} \\
\hline & Antibiotic stewardship & 1997 & {$[67,78,83-88]$} \\
\hline & $\begin{array}{l}\text { Barrier precautions } \\
\text { (i.e. not specified) }\end{array}$ & 2000 & {$[85]$} \\
\hline \multirow{11}{*}{$\begin{array}{l}\text { HCAl in } \\
\text { general }\end{array}$} & Hand hygiene & 1999 & {$[89,90]$} \\
\hline & Isolation & 2005 & {$[77,91]$} \\
\hline & HCW cohorting & 2006 & {$[77,90]$} \\
\hline & Screening & 1999 & [89] \\
\hline & Vaccination & 2008 & {$[77]$} \\
\hline & $\begin{array}{l}\text { Barrier precautions } \\
\text { (i.e. not specified) }\end{array}$ & 2007 & {$[79]$} \\
\hline & Patient cohorting & 2005 & {$[91,92]$} \\
\hline & $\begin{array}{l}\text { Environmental } \\
\text { cleaning }\end{array}$ & 2007 & {$[92]$} \\
\hline & Antibiotic prophylaxis & 2007 & {$[79]$} \\
\hline & Antibiotic stewardship & 2008 & {$[93]$} \\
\hline & HCW cohorting & 2005 & {$[91]$} \\
\hline HIV & $\begin{array}{l}\text { Sterilization of medical } \\
\text { appliances }\end{array}$ & 1999 & [94] \\
\hline \multirow{3}{*}{$\begin{array}{l}\text { Influenza } \\
\text { or ILI }\end{array}$} & Vaccination & 2008 & {$[95-97]$} \\
\hline & Prophylaxis & 2009 & {$[98]$} \\
\hline & Other & 2008 & {$[99,100]$} \\
\hline Pertussis & Vaccination & 2009 & {$[72,101]$} \\
\hline
\end{tabular}

Table 2 Healthcare infection control interventions evaluated by a modelling framework (1997-2011) (Continued)

\begin{tabular}{llll}
\hline Rotavirus & Hand hygiene & 2011 & {$[81]$} \\
& HCW cohorting & 2011 & {$[81]$} \\
& Vaccination & 2011 & {$[81]$} \\
SARS & Isolation & 2007 & {$[102]$} \\
& Barrier precautions & 2005 & {$[74]$} \\
& (i.e. not specified) & & \\
TB & Isolation & 2007 & {$[75]$} \\
& HIV treatment & 2007 & {$[75]$} \\
& Air ventilation & 2007 & {$[75]$} \\
& Facial mask & 2007 & {$[75]$} \\
\hline
\end{tabular}

others included subjective comparison of the model predictions (on infection transmission) with genotype data $[50,53,75]$.

\section{Setting and interaction between settings}

Mathematical models of HCAIs have primarily been set in a single ward (49\%, 47 studies), with the intensive care unit (ICU) being the most frequent setting modelled (26\%, 25 studies) [14,16,22,28,29,31,32,36,40-42,45,49,52,53,55, $63,65,72,79,82,91,101,107,108]$ or a simplified hospital setting, lacking any further ward structure (31\%, 30 studies) $[12,13,24,27,33,34,38,39,45,46,51,58,60,64,66,68,69,74,77,78-$ $, 83-88,93,94,97,109]$. More recent studies however, have incorporated the interaction between general wards and the ICU $[23,43,69]$ or between different wards [11]. Although these ward or hospital-based models do not usually treat the hospital as a closed system (i.e. hospital admission and discharge rates from and to a 'general community' are frequently included), transfer patterns between healthcare institutes are rarely considered [19,20,25,70,71,73], as are transmission dynamics within settings outside the healthcare facilities. The interaction between community and hospital transmission has been included for MRSA $[30,35]$, antimicrobial resistant bacteria as a whole [67], Severe Acute Respiratory Syndrome [76,102] and tuberculosis [75]. Hence any possible long-term feedback between the hospital and other settings is not taken into account. Only two models concerned nosocomial transmission in a LTCF setting alone, i.e. of influenza [98] and norovirus [104] respectively.

\section{Discussion}

Models of MRSA transmission dominate the literature, followed by VRE, although to a considerably lesser extent. Both have been the subject of national surveillance and infection control policies in a variety of developed countries [110-112]. This may account 


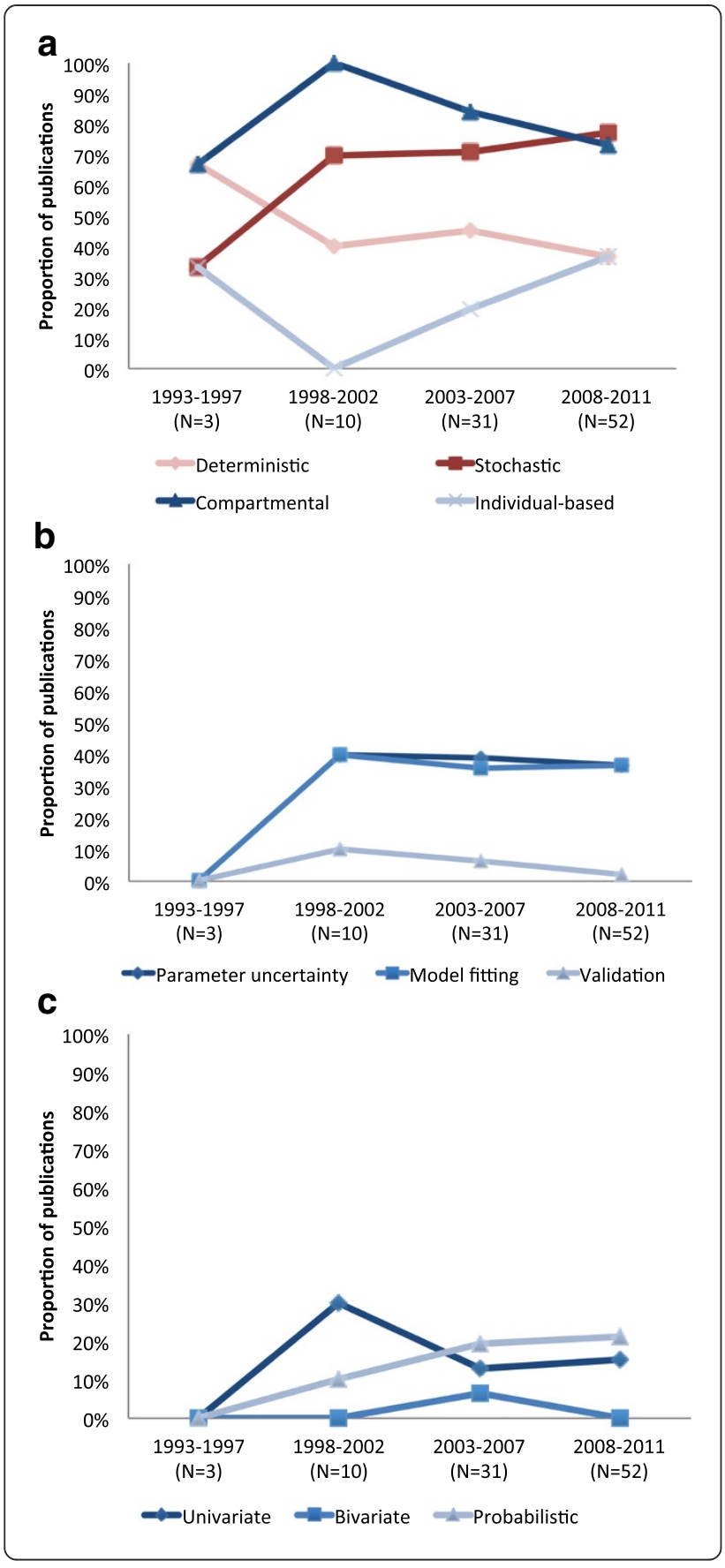

Figure 5 Development of HCAI model methods used over time (1993-2011). Application of key modelling characteristics and development over time. Figure 5a: Model approach Proportion of models using a deterministic vs. stochastic and a compartmental vs individual-based modelling approach by the total number of publications in each time period. Note that the categories are not exclusive, i.e. whereas all individual-based models identified are stochastic, compartmental models may be deterministic or stochastic. Moreover, a proportion of studies use a combination of the above listed modelling approaches (e.g. a deterministic compartmental model complemented by a stochastic individual-based model). Figure $5 b$ Model methods Proportion of models that are fitted to data, have included uncertainty and are validated by consultation of two different datasets by total number of publications in each time period. Figure $5 \mathrm{c}$ Methods used for characterising parameter uncertainty: Proportion of models that have employed uni-variate, vs bi-variate vs probabilistic sensitivity analysis by total number of publications that incorporated parameter uncertainty in each time period.

for the relative abundance of modelling studies. Despite causing a high burden and being the subject of national control policies [113,114], C. difficile transmission has seldom been modelled. Similarly, bloodstream infections due to third-generation cephalosporin-resistant E. coli, which have been estimated to cause $\sim 2,700$ excess deaths and 120,000 extra bed days in Europe in 2007 have been considered by only one study [65]. For comparison, MRSA was estimated to cause $~ 5,500$ deaths and 256,000 additional bed days in Europe [115], yet has been the subject of over 30 studies. It seems then that the occurrence of models does not necessarily correlate to the burden of disease. This is also true in low and middle income countries, where a recently published systematic review [116,117] demonstrated significantly higher prevalence of HCAIs than in high income countries; however, very few modelling studies have tackled the problems of HCAI in less developed settings.

In terms of model methods, considerable changes can be identified over time. After the introduction of the first deterministic HCAI modelling study, inclusion of stochasticity has become common practice. The majority of the HCAI models evaluate infection control policies, for which sound model parameterisation and sensitivity analyses are required for reliable predictions. The use of more sophisticated methods for model parameterisation (e.g. MCMC) and uncertainty analysis has become increasingly common.

HCAI models have also increased in complexity regarding the settings modelled. Although the majority of the models have considered a single ward (often ICUs), the apparent emergence of transmission of typical HCAIs in the community, in particular of MRSA [118], have resulted in models which consider the transmission of HCAI from a more holistic approach. 


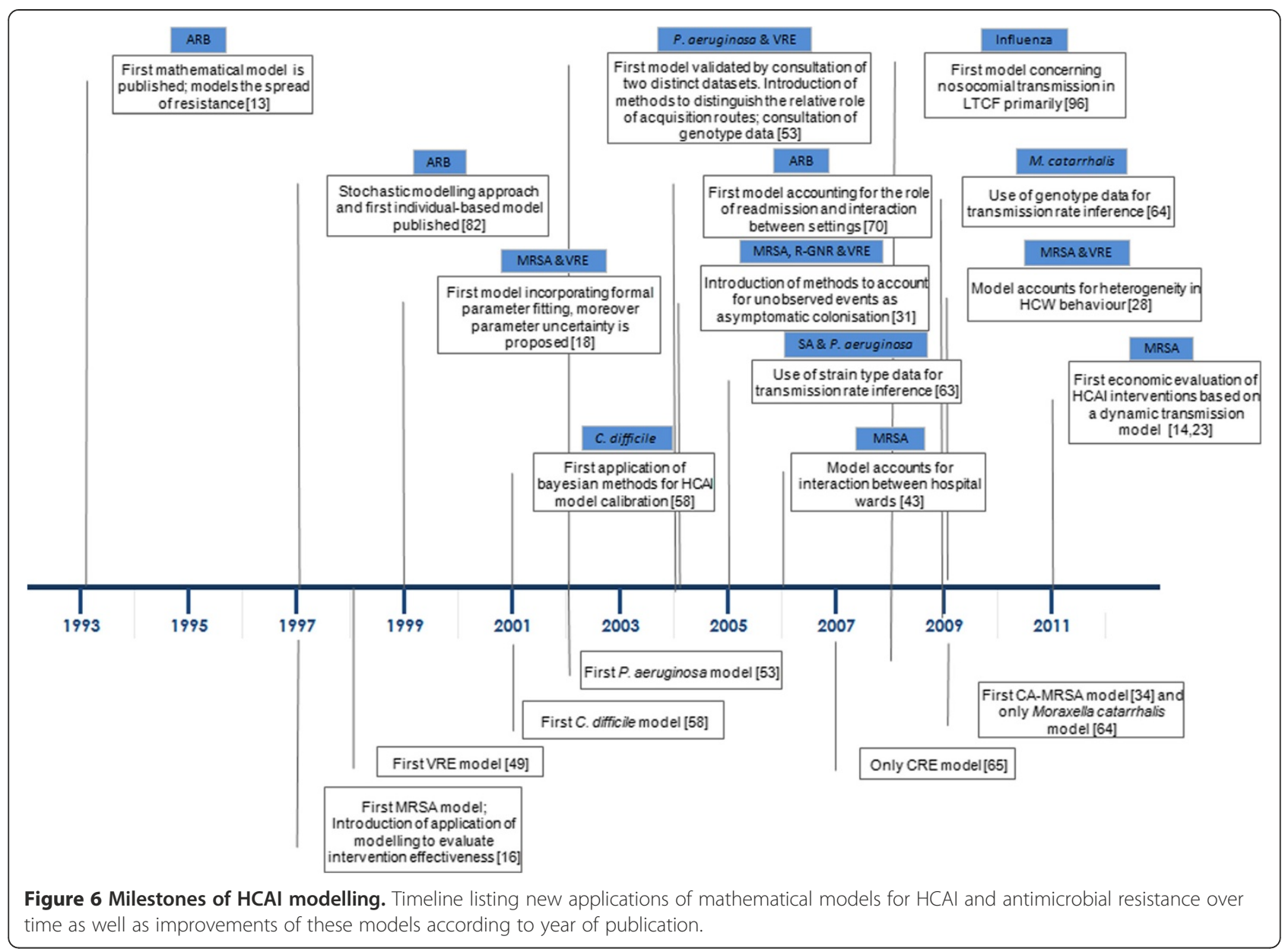

As the long-term feedback loop related to hospital discharge and readmission of colonised patients and spread of HCAI pathogens in the community or settings as LTCFs can effect HCAI transmission dynamics $[19,70,119]$, such an approach can aid in providing a realistic estimate of existing and new infection control strategies' effectiveness.

This review has some limitations. First of all we have exclusively considered peer-reviewed publications in English. This might have resulted in a slight inaccuracy in our results, e.g. with regards to the modelling of particular pathogens in alternative national settings. We were exclusively interested in models exploring the patient-to-patient transmission of HCAI and antimicrobial resistance within healthcare settings (either directly, or mediated by healthcare workers and/or the healthcare environment). This has resulted in the exclusion of a higher number of models that elucidate the dynamics of antimicrobial resistance in its own right, which are summarised elsewhere $[120,121]$. Moreover, this review intended to provide overall trends in the field of HCAI modelling, rather than a detailed account of the quality of individual models and of what these models have shown, which could be a valid future area of investigation.
Compartmental models (which group individuals in classes) have predominated the field of HCAI modelling. The emergence of individual-based modelling allows for more realistic modelling of healthcare worker-patient contact (e.g. super spreading events) or incorporation of heterogeneity in transmission risk profiles of patients. However, these approaches are computationally far more intensive, are difficult to fit to data, and the inclusion of additional factors makes more demand on the data available. Detailed level data such as observed healthcare worker-patient contact collected for example via motebased sensor networks, as has been done recently [122], could help parameterise such more complex models.

Moreover, recent technological developments in microbiology have resulted in enhanced access to pathogen sequence data, which could help to further improve HCAI models. Such data are beginning to inform disease outbreaks e.g. of avian influenza A (H7N7) [123] and Foot-and-Mouth disease [124]. Importantly, the increasingly routine use of sequencing of genetic material for epidemiological purposes can provide valuable insight, such as aiding in the understanding of the role of asymptomatic carriers in transmission (e.g. of C. difficile) and evolution of antimicrobial resistance. 


\section{Conclusions}

Transmission models concerning HCAI have showed a general enhancement in complexity, but have been almost completely limited to high-income settings, and have strongly focused on MRSA transmission in hospital settings. Further improvements in the availability of data and statistical methods could enhance the insight gained from these models.

\section{Additional file}

\section{Additional file 1: Search terms MEDLINE.}

\section{Abbreviations}

ARB: Antimicrobial resistant bacteria; CRE: Cephalosporin-resistant Enterobacteriaceae; ESBL: Extended-spectrum beta-lactamases; HCAI: Healthcare-associated infections; ICU: Intensive care unit; LLI: Influenzalike illness; LHS: Latin Hybercube Sampling; LTCF: Long-term care facility; MCMC: Markov Chain Monte Carlo; MRSA: Methicillin-resistant Staphylococcus aureus; R-GNR: Third generation cephalosporin-resistant Gram-negative rods; TB: Tuberculosis; VRE: Vancomycin-resistant Enterococcus.

\section{Competing interests}

The authors declare that they have no competing interests.

\section{Authors' contributions}

EvK developed the search strategy in collaboration with JR, and conducted a title-abstract screening, independent from a shared title-abstract screening by MJ, SD and WJE. Full text evaluation was conducted by EvK and in case of uncertainty, discussion took place with JR. EvK wrote the manuscript with significant contributions from the other authors. All authors have read and approved the final manuscript.

\section{Acknowledgement}

The authors are grateful to the referees for their valuable suggestions and advice. This work was supported by the Healthcare Infection Society.

Received: 29 November 2012 Accepted: 21 June 2013

Published: 28 June 2013

\section{References}

1. European Centre of Diseases Control: Annual Epidemiological Report on Communicable Diseases in Europe 2008: Report on the State of Communicable Diseases in the EU and EEAVEFTA Countries. Stockholm: European Centre of Disease Control; 2008.

2. MRSA and MSSA bacteraemia and C. difficile infection mandatory data (official statistics). http://www.hpa.org.uk/Topics/InfectiousDiseases/InfectionsAZ/ HCAI/LatestPublicationsFromMandatorySurveillanceMRSACDIAndGRE/.

3. Walker AS, Eyre DW, Wyllie DH, Dingle KE, Harding RM, O'Connor L, Griffiths D, Vaughan A, Finney J, Wilcox MH, Crook DW, Peto TE A: Characterisation of clostridium difficile hospital ward-based transmission using extensive epidemiological data and molecular typing. PLoS Med 2012, 9:e1001172.

4. Riggs MM, Sethi AK, Zabarsky TF, Eckstein EC, Jump RLP, Donskey CJ: Asymptomatic carriers are a potential source for transmission of epidemic and nonepidemic clostridium difficile strains among long-term care facility residents. Clin Infect Dis 2007, 45:992-998.

5. Hensgens MPM, Keessen EC, Squire MM, Riley TV, Koene MGJ, de Boer E, Lipman $\sqcup$ A, Kuijper EJ: Clostridium difficile infection in the community: a zoonotic disease? Clin Microbiol Infect 2012, 67:1-11.

6. Khanna S, Pardi DS, Aronson SL, Kammer PP, Orenstein R, Sauver JLS, Harmsen WS, Zinsmeister AR: The Epidemiology of Community-Acquired Clostridium diffi cile Infection: a Population-Based Study. Am J Gastroenterol 2011, 107:89-95.

7. Braga TM, Pomba C, Lopes MFS: High-level vancomycin resistant Enterococcus faecium related to humans and pigs found in dust from pig breeding facilities. Vet Microbio/ 2013, 161:344-349.
8. Health Protection Agency: English National Point Prevalence Survey on Healthcare-associated Infections and Antimicrobial Use, 2011 - Preliminary Data. London: Health Protection Agency; 2011:1-140.

9. Jit M, Brisson M: Modelling the Epidemiology of Infectious Diseases for Decision Analysis A Primer. 2011, 29:371-386.

10. Grundmann $\mathrm{H}$, Hellriegel B: Mathematical modelling: a tool for hospital infection control. Lancet Infect Dis 2006, 6:39-45.

11. Ancel Meyers L, Newman MEJ, Martin M, Schrag S: Applying network theory to epidemics: control measures for Mycoplasma pneumoniae outbreaks. Emerg Infect Dis 2003, 9:204-10.

12. McBryde E, McElwain DLS: A mathematic model investigating the impact of an environmental reservoir on the prevalence and control of vancomycin-resistant enterococci. J Infect Dis 2006, 193:1473-1474.

13. Massad E, Lundberg S, Yang HM: Modeling and simulating the evolution of resistance against antibiotics. Int J Biomed Comput 1993, 33:65-81.

14. Robotham JV, Graves N, Cookson BD, Barnett AG, Wilson JA, Edgeworth JD, Batra R, Cuthbertson BH, Cooper BS: Screening, isolation, and decolonisation strategies in the control of meticillin resistant Staphylococcus aureus in intensive care units: cost effectiveness evaluation. BMJ 2011, 343

15. Wang J, Wang L, Magal P, Wang Y, Zhuo J, Lu X, Ruan S: Modelling the transmission dynamics of meticillin-resistant Staphylococcus aureus in Beijing Tongren hospital. J Hosp Infect 2011, 79:302-308.

16. Sebille $V$, Chevret $S$, Valleron A: Modeling the spread of resistant nosocomial pathogens in an intensive-care unit. Infect Control Hosp Epidemiol 1997, 18:84-92.

17. Milazzo L, Bown JL, Eberst A, Phillips G, Crawford JW: Modelling of Healthcare Associated Infections: a study on the dynamics of pathogen transmission by using an individual-based approach. Comput Methods Programs Biomed 2011, 104:260-265.

18. Austin DJ, Anderson RM: Transmission dynamics of epidemic methicillinresistant Staphylococcus aureus and vancomycin-resistant enterococci in England and Wales. J Infect Dis 1999, 179:883-891.

19. Lesosky M, McGeer A, Simor A, Green K, Low DE, Raboud J: Effect of patterns of transferring patients among healthcare institutions on rates of nosocomial methicillin-resistant Staphylococcus aureus transmission: a Monte Carlo simulation. Infect Control Hosp Epidemiol 2011, 32:136-147.

20. Lee BY, McGlone SM, Wong KF, Yilmaz SL, Avery TR, Song Y, Christie R, Eubank S, Brown ST, Epstein JM, Parker Jl, Burke DS, Platt R, Huang SS: Modeling the spread of methicillin-resistant staphylococcus aureus (mrsa) outbreaks throughout the hospitals in orange county, California. Infect Control Hosp Epidemiol 2011, 32:562-572.

21. Kardas-Sloma L, Boelle PY, Opatowski L, Brun-Buisson C, Guillemot D, Temime L: Impact of antibiotic exposure patterns on selection of community-associated methicillin-resistant Staphylococcus aureus in hospital settings. Antimicrob Agents Chemother 2011, 55:4888-4895

22. Christopher S, Verghis RM, Antonisamy B, Sowmyanarayanan TV, Brahmadathan KN, Kang G, Cooper BS: Transmission dynamics of methicillin-resistant Staphylococcus aureus in a medical intensive care unit in India. PLOS ONE [Electronic Resource] 2011, 6.

23. Hubben G, Bootsma M, Luteijn M, Glynn D, Bishai D, Bonten M, Postma M: Modelling the costs and effects of selective and universal hospital admission screening for methicillin-resistant Staphylococcus aureus. PLoS ONE [Electronic Resource] 2011, 6:e14783.

24. Bootsma MCJ, Wassenberg MWM, Trapman P, Bonten MJM: The nosocomial transmission rate of animal-associated ST398 meticillin-resistant Staphylococcus aureus. J R Soc Interface 2011, 8:578-584.

25. Barnes SL, Harris AD, Golden BL, Wasil EA, Furuno JP: Contribution of interfacility patient movement to overall methicillin-resistant Staphylococcus aureus prevalence levels. Infect Control Hosp Epidemiol 2011, 32:1073-1078.

26. Meng Y, Davies R, Hardy K, Hawkey P: An application of agent-based simulation to the management of hospital-acquired infection. Journal of Simulation 2010, 4:60-67

27. Pressley J, D'Agata EMC, Webb GF: The effect of co-colonization with community-acquired and hospital-acquired methicillin-resistant 
Staphylococcus aureus strains on competitive exclusion. $J$ Theor Biol 2010, 264:645-656.

28. Temime L, Opatowski L, Pannet Y, Brun-Buisson C, Boelle PY, Guillemot D: Peripatetic health-care workers as potential superspreaders. Proc Natl Acad Sci USA 2009, 106:18420-18425.

29. Grundmann H, Hori S, Winter B, Tami A, Austin DJ: Risk factors for the transmission of methicillin-resistant Staphylococcus aureus in an adult intensive care unit: fitting a model to the data. J Infect Dis 2002, 185:481-488.

30. Skov RL, Jensen KS: Community-associated meticillin-resistant Staphylococcus aureus as a cause of hospital-acquired infections. J Hosp Infect 2009, 73:364-370.

31. Cooper B, Lipsitch M: The analysis of hospital infection data using hidden Markov models. Biostatistics 2004, 5:223-237.

32. Kypraios T, O'Neill PD, Huang SS, Rifas-Shiman SL, Cooper BS: Assessing the role of undetected colonization and isolation precautions in reducing Methicillin-Resistant Staphylococcus aureus transmission in intensive care units. BMC Infect Dis 2009, 10.

33. Webb GF, Horn MA, D'Agata EMCD, Moellering RC, Ruan S: Competition of hospital-acquired and community-aqcuired methicillin-resistant Staphylococcus aureus strains in hospitals. J Biol Dyn 2010, 1:115-129.

34. D'Agata EMC, Webb GF, Horn MA, Moellering RC Jr, Ruan S: Modeling the invasion of community-acquired methicillin-resistant Staphylococcus aureus into hospitals. Clin Infect Dis 2009, 48:274-284

35. Cooper BS, Medley GF, Stone SP, Kibbler CC, Cookson BD, Roberts JA, Duckworth G, Lai R, Ebrahim S: Methicillin-resistant Staphylococcus aureus in hospitals and the community: stealth dynamics and control catastrophes. Proc Natl Acad Sci USA 2004, 101:10223-10228.

36. Drovandi CC, Pettitt AN: Multivariate Markov process models for the transmission of methicillin-resistant Staphylococcus aureus in a hospital ward. Biometrics 2008, 64:851-859.

37. Beggs CB, Shepherd SJ, Kerr KG: Increasing the frequency of hand washing by healthcare workers does not lead to commensurate reductions in staphylococcal infection in a hospital ward. BMC Infect Dis 2008, 8:114.

38. Robotham JV, Scarff CA, Jenkins DR, Medley GF: Meticillin-resistant Staphylococcus aureus (MRSA) in hospitals and the community: model predictions based on the UK situation. J Hosp Infect 2007, 65(2):93-99.

39. Robotham JV, Jenkins DR, Medley GF: Screening strategies in surveillance and control of methicillin-resistant Staphylococcus aureus (MRSA). Epidemiol Infect 2007, 135:328-342.

40. McBryde ES, Pettitt AN, McElwain DLS: A stochastic mathematical model of methicillin resistant Staphylococcus aureus transmission in an intensive care unit: predicting the impact of interventions. J Theor Biol 2007, 245:470-481

41. Forrester ML, Pettitt AN, Gibson GJ: Bayesian inference of hospitalacquired infectious diseases and control measures given imperfect surveillance data. Biostatistics 2007, 8:383-401.

42. Forrester M, Pettitt AN: Use of stochastic epidemic modeling to quantify transmission rates of colonization with methicillin-resistant Staphylococcus aureus in an intensive care unit. Infect Control Hosp Epidemiol 2005, 26:598-606

43. Bootsma MCJ, Diekmann O, Bonten MJM: Controlling methicillinresistant Staphylococcus aureus: quantifying the effects of interventions and rapid diagnostic testing. Proc Natl Acad Sci USA 2006, 103:5620-5625.

44. Raboud J, Saskin R, Simor A, Loeb M, Green K, Low DE, McGeer A: Modeling transmission of methicillin-resistant Staphylococcus aureus among patients admitted to a hospital. Infect Control Hosp Epidemiol 2005, 26:607-615

45. Barnes $\mathrm{S}$, Golden B, Wasil E: MRSA transmission reduction using agent-based modeling and simulation. INFORMS J Comput 2010, 22:635-646.

46. D'Agata EMC, Webb GF, Pressley J: Rapid emergence of cocolonization with community-acquired and hospital-acquired methicillin-resistant Staphylococcus aureus strains in the hospital setting. Mathematical Modelling of Natural Phenomena 2010, 5:76-93.
47. Wolkewitz M, Dettenkofer M, Bertz H, Schumacher M, Huebner J: Environmental contamination as an important route for the transmission of the hospital pathogen VRE: modeling and prediction of classical interventions. Infectious Diseases: Research and Treatment 2008, 1:3-11.

48. Cooper BS, Medley GF, Bradley SJ, Scott GM: An augmented data method for the analysis of nosocomial infection data. Am J Epidemiol 2008 168:548-557.

49. Austin DJ, Bonten MJM: Vancomycin-resistant enterococci in intensive care hospital settings. Memorias do Instituto Oswaldo Cruz 1998, 93:587-588

50. McBryde ES, Pettitt AN, Cooper BS, McElwain DLS: Characterizing an outbreak of vancomycin-resistant enterococci using hidden Markov models. J R Soc Interface 2007, 4:745-754.

51. D'Agata EMC, Webb G, Horn M: A mathematical model quantifying the impact of antibiotic exposure and other interventions on the endemic prevalence of vancomycin-resistant enterococci. J Infect Dis 2005, 192:2004-2011.

52. Perencevich EN, Fisman DN, Lipsitch M, Harris AD, Morris JG Jr, Smith DL: Projected benefits of active surveillance for vancomycinresistant enterococci in intensive care units. Clin Infect Dis 2004 38:1108-1115

53. Pelupessy I, Bonten MJM, Diekmann O: How to assess the relative importance of different colonization routes of pathogens within hospital settings. Proc Natl Acad Sci USA 2002, 99:5601-5605.

54. D'Agata EMC, Horn MA, Webb GF: The impact of persistent gastrointestinal colonization on the transmission dynamics of vancomycin-resistant enterococci. J Infect Dis 2002, 185:766-773.

55. Austin DJ, Bonten MJ, Weinstein RA, Slaughter S, Anderson RM: Vancomycin-resistant enterococci in intensive-care hospital settings: transmission dynamics, persistence, and the impact of infection control programs. Proc Natl Acad Sci USA 1999, 96:6908-6913.

56. Ortiz A, Banks HT, Castillo-Chavez C, Chowell G, Wang X: A discrete events delay differential system model for transmission of Vancomycin-resistant enterococcus (VRE) in hospitals. Journal of Inverse and III-Posed Problems 2010, 18:787-821.

57. Ortiz AR, Banks HT, Castillo-Chavez C, Chowell G, Wang X: A deterministic methodology for estimation of parameters in dynamic markov chain models. J Biol Syst 2011, 19:71-100.

58. Starr JM, Campbell A: Mathematical modeling of Clostridium difficile infection. Clin Microbiol Infect 2001, 7:432-437.

59. Starr JM, Campbell A, Renshaw E, Poxton IR, Gibson GJ: Spatio-temporal stochastic modelling of Clostridium difficile. J Hosp Infect 2009, 71:49-56

60. Lanzas C, Dubberke ER, Lu Z, Reske KA, Grohn YT: Epidemiological model for Clostridium difficile transmission in healthcare settings. Infect Control Hosp Epidemiol 2011, 32:553-561.

61. Otto S, Day T: A Biologist's Guide to Mathematical Modelling in Ecology and Evoluation. 1st edition. Oxfordshire: Princeton University Press; 2007:76.

62. Vanni T, Karnon J, Madan J, White RG, Edmunds WJ, Foss AM, Legood R Calibrating Models in Economic Evaluation. PharmacoEconomics 2011, 29:35-49.

63. Jackson BR, Thomas A, Carroll KC, Adler FR, Samore MH: Use of strain typing data to estimate bacterial transmission rates in healthcare settings. Infect Control Hosp Epidemiol 2005, 26:638-645.

64. Leman SC, Levy F, Walker ES: Modeling the spread of infectious disease using genetic information within a marked branching process. Stat Med 2009, 28:3626-3642.

65. Bootsma MCJ, Bonten MJM, Nijssen S, Fluit AC, Diekmann O: An algorithm to estimate the importance of bacterial acquisition routes in hospital settings. Am J Epidemiol 2007, 166:841-51.

66. Kwok KO, Leung GM, Lam WY, Riley S: Using models to identify routes of nosocomial infection: a large hospital outbreak of SARS in Hong Kong. Proc R Soc Lond B Biol Sci 2007, 274:611-617.

67. Kouyos RD, Abel Zur Wiesch P, Bonhoeffer S: On being the right size: the impact of population size and stochastic effects on the evolution of drug resistance in hospitals and the community. PLOS Pathog 2011, 7:e1001334 
68. Webb GF, D'Agata EMC, Magal P, Ruan S: A model of antibiotic-resistant bacterial epidemics in hospitals. Proc Natl Acad Sci USA 2005, 102:13343-13348.

69. Lee BY, McGlone SM, Bailey RR, Wettstein ZS, Umscheid CA, Muder RR: Economic impact of outbreaks of norovirus infection in hospitals. Infect Control Hosp Epidemiol 2011, 32:191-193.

70. Smith DL, Dushoff J, Perencevich EN, Harris AD, Levin SA: Persistent colonization and the spread of antibiotic resistance in nosocomial pathogens: resistance is a regional problem. Proc Natl Acad Sci USA 2004 101:3709-3714

71. Donker T, Wallinga J, Grundmann H: Patient referral patterns and the spread of hospital-acquired infections through national health care networks. PLoS Comput Biol 2010, 6:e1000715.

72. Greer AL, Fisman DN: Use of models to identify cost-effective interventions: Pertussis vaccination for pediatric health care workers. Pediatrics 2011, 128:e591-e599.

73. Smith DL, Levin SA, Laxminarayan R: Strategic interactions in multiinstitutional epidemics of antibiotic resistance. Proc Natl Acad Sci USA 2005, 102:3153-3158

74. Nishiura H, Kuratsuji T, Quy T, Phi NC, Van Ban V, Ha LD, Long HT, Yanai H, Keicho N, Kirikae T, Sasazuki T, Anderson RM: Rapid awareness and transmission of severe acute respiratory syndrome in Hanoi French Hospital, Vietnam. AmJTrop Med Hyg 2005, 73:17-25.

75. Basu S, Andrews JR, Poolman EM, Gandhi NR, Shah NS, Moll A, Moodley P, Galvani AP, Friedland GH: Prevention of nosocomial transmission of extensively drug-resistant tuberculosis in rural South African district hospitals: an epidemiological modelling study. Lancet 2007, 370:1500-1507.

76. Cori A, Boelle PY, Thomas G, Leung GM, Valleron AJ: Temporal variability and social heterogeneity in disease transmission: the case of SARS in Hong Kong. PLoS Comput Biol 2009, 5:e1000471.

77. Ueno T, Masuda N: Controlling nosocomial infection based on structure of hospital social networks. J Theor Biol 2008, 254:655-666

78. Bergstrom CT, Lo M, Lipsitch M: Ecological theory suggests that antimicrobial cycling will not reduce antimicrobial resistance in hospitals. Proc Natl Acad Sci USA 2004, 101:13285-13290.

79. Boldin B, Bonten MJM, Diekmann O: Relative effects of barrier precautions and topical antibiotics on nosocomial bacterial transmission: results of multi-compartment models. Bull Math Biol 2007, 69:2227-2248

80. Kouyos RD, Abel Zur Wiesch P, Bonhoeffer S: Informed switching strongly decreases the prevalence of antibiotic resistance in hospital wards. PLOS Comput Biol 2011, 7:e1001094.

81. Kribs-Zaleta CM, Jusot JF, Vanhems P, Charles S: Modeling Nosocomial Transmission of Rotavirus in Pediatric Wards. Bull Math Biol 2011. 73:1413-1442

82. Sebille $\mathrm{V}$, Valleron AJ: A computer simulation model for the spread of nosocomial infections caused by multidrug-resistant pathogens. Comput Biomed Res 1997, 30:307-322.

83. Haber MJ, Levin BR, Kramarz P: Antibiotic control of antibiotic resistance in hospitals: a simulation study. BMC Infect Dis 2010, 10. 25 August 2010.

84. Friedman A, Ziyadi N, Boushaba K: A model of drug resistance with infection by health care workers. Mathematical Biosciences \& Engineering: MBE 2010, 7:779-792.

85. Lipsitch M, Bergstrom CT, Levin BR: The epidemiology of antibiotic resistance in hospitals: paradoxes and prescriptions. Proc Natl Acad SC USA 2000, 97:1938-1943.

86. D'Agata EMC, Magal P, Olivier D, Ruan S, Webb GF: Modeling antibiotic resistance in hospitals: the impact of minimizing treatment duration. J Theor Biol 2007, 249:487-499.

87. Reluga TC: Simple models of antibiotic cycling. Math Med Biol 2005, 22:187-208.

88. Chowa K, Wanga X, Curtiss R, Castillo-Chavez C: Evaluating the efficacy of antimicrobial cycling programmes and patient isolation on dual resistance in hospitals. J Biol Dyn 2011, 5:27-43.

89. Cooper BS, Medley GF, Scott GM: Preliminary analysis of the transmission dynamics of nosocomial infections: stochastic and management effects. J Hosp Infect 1999, 43:131-147.

90. Beggs CB, Noakes CJ, Shepherd SJ, Kerr KG, Sleigh PA, Banfield K: The influence of nurse cohorting on hand hygiene effectiveness. Am J Infect Control 2006, 34:621-626.
91. Hotchkiss JR, Strike DG, Simonson DA, Broccard AF, Crooke PS: An agentbased and spatially explicit model of pathogen dissemination in the intensive care unit. Crit Care Med 2005, 33:164-168.

92. Hotchkiss JR, Holley P, Crooke PS: Analyzing pathogen transmission in the dialysis unit: time for a (schedule) change? Clinical Journal of The American Society of Nephrology: CJASN 2007, 2:1176-1185.

93. Massad E, Burattini MN, Coutinho FAB: An optimization model for antibiotic use. Appl Math Comput 2008, 201:161-167.

94. Bakhir VM, Grishin VP, Panicheva SA, Toloknov VI: Assessment of the effectiveness of medical instruments sterilization by electrochemically activated solutions and computer modeling of the dynamics of hospital infections. [Russian] Otsenka effektivnosti sterilizatsii meditsinskogo instrumentariia elektro. Meditsinskaia Tekhnika 1999:14-16.

95. van den Dool C, Bonten MJM, Hak E, Wallinga J: Modeling the effects of influenza vaccination of health care workers in hospital departments. vaccine 2009, 27:6261-6267.

96. van den Dool C, Bonten MJM, Hak E, Heijne JCM, Wallinga J: The effects of influenza vaccination of health care workers in nursing homes: insights from a mathematical model. PLoS Medicine / Public Library of Science 2008, 5:e200.

97. Polgreen PM, Tassier TL, Pemmaraju SV, Segre AM: Prioritizing healthcare worker vaccinations on the basis of social network analysis. Infect Control Hosp Epidemio/ 2010, 31:893-900.

98. van den Dool C, Hak E, Bonten MJM, Wallinga J: A model-based assessment of oseltamivir prophylaxis strategies to prevent influenza in nursing homes. Emerg Infect Dis 2009, 15:1547-1555.

99. Laskowski M, Demianyk BCP, Witt J, Mukhi SN, Friesen MR, McLeod RD: Agent-based modeling of the spread of influenza-like illness in an emergency department: a simulation study. IEEE transactions on information technology in biomedicine: a publication of the IEEE Engineering in Medicine and Biology Society 2011, 15:877-89.

100. Nuno M, Reichert TA, Chowell G, Gumel AB: Protecting residential care facilities from pandemic influenza. Proc Natl Acad Sci USA 2008, 105:10625-10630.

101. Greer AL, Fisman DN: Keeping vulnerable children safe from pertussis: preventing nosocomial pertussis transmission in the neonatal intensive care unit. Infect Control Hosp Epidemiol 2009, 30:1084-1089.

102. Fukutome A, Watashi K, Kawakami N, Ishikawa H: Mathematical modeling of severe acute respiratory syndrome nosocomial transmission in Japan: the dynamics of incident cases and prevalent cases. Microbiol Immunol 2007, 51:823-832.

103. O'Neill PD: Introduction and snapshot review: relating infectious disease transmission models to data. Stat Med 2010, 29:2069-77.

104. Vanderpas J, Louis J, Reynders M, Mascart G, Vandenberg O: Mathematical model for the control of nosocomial norovirus. J Hosp Infect 2009, 71:214-222.

105. Bilcke J, Beutels P, Brisson M, Jit M: Accounting for methodological, structural, and parameter uncertainty in decision-analytic models: a practical guide. Medical decision making : an international journal of the Society for Medical Decision Making 2011, 31:675-92.

106. Oakley JE, Hagan AO: Probabilistic sensitivity analysis of complex models: a Bayesian approach; 2004:751-769.

107. Artalejo JR, Economou A, Lopez-Herrero MJ: On the number of recovered individuals in the SIS and SIR stochastic epidemic models. Math Biosci 2010, 228:45-55.

108. Beardmore RE, Pena-Miller R: Rotating antibiotics selects optimally against antibiotic resistance, in theory. Mathematical Biosciences \& Engineering: MBE 2010, 7:527-552

109. Noakes CJ, Beggs CB, Sleigh PA, Kerr KG: Modelling the transmission of airborne infections in enclosed spaces. Epidemiol Infect 2006, 134:1082-1091.

110. Köck R, Becker K, Cookson B, van Gemert-Pijnen JE, Harbarth S, Kluytmans J, Mielke M, Peters G, Skov RL, Struelens MJ, Tacconelli E, Navarro Torné A, Witte W, Friedrich AW: Methicillin-resistant Staphylococcus aureus (MRSA): burden of disease and control challenges in Europe. Euro surveillance: bulletin européen sur les maladies transmissibles = European communicable disease bulletin 2010, 15:19688

111. MRSA surveillance. http://www.cdc.gov/mrsa/statistics/mrsa-surveillancesummary.html. 
112. Surveillance for Methicillin-resistant Staphylococcus aureus (MRSA) in Patients Hospitalized in Canadian Acute-Care Hospitals Participating in CNISP 20062007 Preliminary Results. http://www.phac-aspc.gc.ca/nois-sinp/reportsrapport/mrsa-sarm_result-eng.php.

113. Dubberke ER, Olsen M a: Burden of Clostridium difficile on the Healthcare System. Clin Infect Dis 2012, 55(suppl 2):S88-S92.

114. Bauer MP, Notermans DW, van Benthem BHB, Brazier JS, Wilcox MH, Rupnik $M$, Monnet $D L$, van Dissel JT, Kuijper EJ: Clostridium difficile infection in Europe: a hospital-based survey. Lancet 2011, 377:63-73.

115. de Kraker ME A, Davey PG, Grundmann H: Mortality and hospital stay associated with resistant Staphylococcus aureus and Escherichia coli bacteremia: estimating the burden of antibiotic resistance in Europe. PLoS Med 2011, 8:e1001104.

116. World Health Organization: Report on the Burden of Endemic Health CareAssociated Infection Worldwide - Clean Care Is Safer Care. Geneva; 2011.

117. Allegranzi B, Bagheri Nejad S, Combescure C, Graafmans W, Attar H, Donaldson $L$, Pittet D: Burden of endemic health-care-associated infection in developing countries: systematic review and meta-analysis. Lancet 2011, 377:228-41.

118. Deleo FR, Otto M, Kreiswirth BN, Chambers HF: Community-associated meticillin-resistant Staphylococcus aureus. Lancet 2010, 375:1557-68.

119. Ricciardi R, Nelson J, Griffith JL, Concannon TW: Do admissions and discharges to long-term care facilities influence hospital burden of Clostridium difficile infection? J Hosp Infect 2012, 80:156-61.

120. Opatowski L, Guillemot D, Boëlle P-Y, Temime L: Contribution of mathematical modeling to the fight against bacterial antibiotic resistance. Curr Opin Infect Dis 2011, 24:279-87.

121. Temime L, Hejblum G, Setbon M, Valleron A: The rising impact of mathematical modelling in epidemiology : antibiotic resistance research as a case study. Epidemiol Infect 2008, 136:289-298.

122. Hornbeck T, Naylor D, Segre AM, Thomas G, Herman T, Polgreen PM: Using sensor networks to study the effect of peripatetic healthcare workers on the spread of hospital-associated infections. J Infect Dis 2012, 206:1549-57.

123. Ypma RJF, Bataille AMA, Stegeman A, Koch G, Wallinga J, van Ballegooijen WM: Unravelling transmission trees of infectious diseases by combining genetic and epidemiological data. Proceedings Biological sciences/The Royal Society 2012, 279:444-5.

124. Morelli MJ, Thébaud G, Chadœuf J, King DP, Haydon DT, Soubeyrand S: A Bayesian Inference Framework to Reconstruct Transmission Trees Using Epidemiological and Genetic Data. PLoS Comput Biol 2012, 8:e1002768,

doi:10.1186/1471-2334-13-294

Cite this article as: van Kleef et al: Modelling the transmission of healthcare associated infections: a systematic review. BMC Infectious Diseases 2013 13:294.

\section{Submit your next manuscript to BioMed Central and take full advantage of:}

- Convenient online submission

- Thorough peer review

- No space constraints or color figure charges

- Immediate publication on acceptance

- Inclusion in PubMed, CAS, Scopus and Google Scholar

- Research which is freely available for redistribution 